\title{
Outcome of Assisted Reproduction Treatment in Women with Extremely Low Antimullerian Hormone (AMH) Levels
}

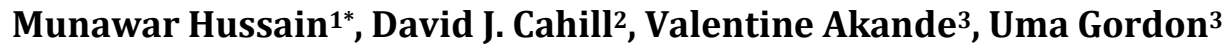 \\ ${ }^{1}$ St. Michael's Hospital, University Hospital Bristol NHS Foundation Trust, Bristol, UK \\ ${ }^{2}$ Academic Unit of Obstetrics and Gynaecology, School of clinical sciences, University of Bristol \& St. Michael's \\ Hospital, Bristol, UK \\ ${ }^{3}$ Bristol Centre for Reproductive Medicine, North Bristol NHS Trust, Bristol, UK \\ Email: ${ }^{*}$ dr 72hussain@yahoo.com, ${ }^{*}$ Munawar.Hussain@UHBristol.nhs.uk, d.j.cahill@bristol.ac.uk, \\ vakande@gmail.com, Uma.gordon@nbt.nhs.uk
}

Received 27 August 2014; revised 25 September 2014; accepted 20 October 2014

Academic Editor: Yasam Kemal Akpak, Ankara Mevki Military Hospital, Turkey

Copyright (C) 2014 by authors and Scientific Research Publishing Inc.

This work is licensed under the Creative Commons Attribution International License (CC BY).

http://creativecommons.org/licenses/by/4.0/

(c) (i) Open Access

\begin{abstract}
Purpose: To evaluate age related ovarian response to controlled ovarian hyperstimulation, clinical pregnancy and ongoing pregnancy rates beyond 20 weeks in women undergoing assisted reproduction treatment (ART) with antimullerian hormone (AMH) levels of $<5$ pmol/l. Methods: Retrospective analysis of data from 63 women with AMH of $<5 \mathrm{pmol} / \mathrm{L}$ who underwent their first assisted reproduction treatment (In-vitro fertilization, IVF and intracytoplasmic sperm injection, ICSI) cycle. Results were analyzed after dividing patients in two groups, group 1 included women of $\leq 38$ years and group $2>38$ years of age. Non parametric variables were expressed as median (Interquartile range) and compared by Kruskal-Wallis test. Categorical variables were expressed as numbers with proportions (\%) and compared by Fisher's exact test. Results: There was no statistical difference in body max index, level of antimullerian hormone (AMH), follicle stimulating hormone (FSH), dose of gonadotrophins used and cycles cancellation rate in two groups. Although number of oocytes retrieved (median 5), clinical pregnancy $(18.4 \%)$ and ongoing pregnancy rate beyond 20 weeks $(18.4 \%)$ was higher in group 1 , there was no statistical difference between the two groups. There was one miscarriage in group 2. Conclusion: Women with extremely low-serum AMH levels can still have clinical pregnancy and ongoing pregnancies beyond 20 weeks after ART, though chances will be lower than women with normal ovarian reserve.
\end{abstract}

\footnotetext{
"Corresponding author.
}

How to cite this paper: Hussain, M., Cahill, D.J., Akande, V. and Gordon, U. (2014) Outcome of Assisted Reproduction Treatment in Women with Extremely Low Antimullerian Hormone (AMH) Levels. Open Journal of Obstetrics and Gynecology, 4, 961-966. http://dx.doi.org/10.4236/ojog.2014.415135 


\section{Keywords}

\section{Extremely Low Antimullerian Hormone, Assisted Reproduction Treatment, Clinical Pregnancy, Ongoing Pregnancy, Miscarriage Rate}

\section{Introduction}

Success at in-vitro fertilization (IVF) is dependent on follicular response which in turn depends on the cohort of follicles available. This cohort is well known to diminish with age and especially after the age of 37 or 38 years [1]. Historically, age has been used as a determinant, and in the last 20 years follicle stimulating hormone (FSH) [2] [3] has been used to test ovarian reserve. More recently, data have emerged about the role of anti-mullerian hormone (AMH) in predicting follicular response, and considerable interest in its role has been experienced.

AMH may identify both extremes of ovarian response. AMH levels correlate with oocyte number retrieved at controlled ovarian hyperstimulation $(\mathrm{COH})$ and treatment may be individualised for optimal cycle outcomes [4]-[9]. Although reduced levels of AMH are associated with reduced ovarian responsiveness [10] and poor success rate at ART [4], the relationship between AMH levels and pregnancy outcome in ART is still not clear [4] [11] [12].

There are limited data on pregnancy and live birth in women with extremely low AMH levels [13]. In this paper, we examine the outcomes of a cohort of women with what would be considered low levels of AMH, and analyse these outcomes by age, specifically the age (38 years) at which Faddy et al. [1] considered to be the main point when ovarian responses might change.

\section{Material and Methods}

Data from 63 women with low AMH levels who underwent their first IVF/ICSI cycle at The Bristol Centre for Reproductive Medicine (BCRM) UK between September 2010 to May 2012 were analysed. Data regarding controlled ovarian hyperstimulation $(\mathrm{COH})$ and cycle outcome were extracted from the centre's secure computer database.

AMH was assayed on any day of the menstrual cycle at patient's convenience using the Generation II AMH (Gen-II AMH assay) enzyme-linked immunosorbent assay kit (Beckman Coulter, Inc. USA). Intra- and interassay coefficients of variation (CV) were $<6 \%$ and $<10 \%$ respectively, lower detection limit at $0.08 \mathrm{ng} / \mathrm{ml}$, and linearity up to $21 \mathrm{ng} / \mathrm{ml}$ for AMH. AMH levels were reported as pmol/L (conversion factor: $1 \mathrm{ng} / \mathrm{ml}=7.14$ pmol/L). Poor response to COH has been noted with AMH levels of $<5$ pmol/L by Nelson et al. (2009) [7] and therefore this level was considered as "Low".

All patients underwent $\mathrm{COH}$ after using the long protocol as we have previously described [14]. Women were treated using the standard operating procedure of the unit. As all women analysed were considered to have low ovarian reserve due to low AMH levels, all of them were treated with 300 iu of recombinant FSH (Gonal F; Merck-Serono Pharmaceuticals Ltd., Feltham, UK) or highly purified FSH (Menopur; Ferring Pharmaceuticals Ltd., West Drayton UK) for COH.

When there were at least 3 leading follicles measuring $\geq 17 \mathrm{~mm}$, recombinant human chorionic gonadotrophin (Ovitrelle, Merck-Serono, UK) 6500 IU was administered subcutaneously. Cycle cancellation was discussed if fewer than three follicles developed after at least two weeks of $\mathrm{COH}$ with maximum dose of FSH. Transvaginal ultrasound guided oocyte retrieval was performed under sedation, 34 - 36 hours after the hCG injection. Progesterone vaginal pessaries (Cyclogest; Shire Pharmaceuticals Ltd., Basingstoke, Hants, UK) 400 mg 12 hourly were prescribed for luteal phase support starting the day after oocyte retrieval. As per local policy, a single or double embryo on day 2 - 3 or a single blastocyst on day 5 - 6 was transferred by soft embryo transfer catheter (Sydney Cook, Limerick, Ireland) depending upon the women's age and number of available embryos Urinary pregnancy test was performed two weeks after embryo transfer if no menstrual period followed. If the test was positive, an early pregnancy ultrasound scan was carried out at $6-7$ weeks gestation to confirm the status of the pregnancy.

\subsection{Statistical Analysis}

To analyse oocyte numbers, clinical pregnancy and ongoing pregnancy beyond 20 weeks, patients were divided 
into two groups according to their age. Group1 included women with $\mathrm{AMH}<5 \mathrm{pmol} / \mathrm{L}$ and age less than 38 years and group 2 included women with $\mathrm{AMH}<5 \mathrm{pmol} / \mathrm{L}$ and age more than 38 years. Data were analyzed using Stats Direct (Stats Direct Ltd., Cheshire, UK). Non parametric variables were expressed as median (Interquartile range) and compared by Kruskal-Wallis test. Categorical variables were expressed as numbers with proportions (\%) and compared by Fisher's exact test. A $P$-value $<0.05$ was considered statistically significant.

\subsection{Ethical Consideration}

All patients gave written consent for surgical procedures and anonymised use of laboratory and clinical data for quality and research purposes.

\section{Results}

There were 63 total patients in this cohort with 38 and 25 patients with ages less than and more than 38 years (Group 1 and 2 respectively). Table 1 shows demographic and hormonal levels in two groups. Both groups were comparable with regards to body mass index (BMI), AMH and FSH values (Table 1). Group 1 included women of relatively younger women with median age of 35 years and Group 2 had relatively older women with median age of 40 years. Three cycles (one in group 1 and two in group 2) were cancelled due to extremely poor ovarian response.

There was complete failure of fertilization in 5 patients (2 in Group 1 and 3 in Group 2). Table 2 summarizes the cycle outcome in the two groups. There was no statistical difference in total dose of gonadotrophins used (iu) and cycle cancellation rate in two groups. In group 1, although more oocytes were retrieved and achieved apparent higher clinical pregnancy (18.4\%) and ongoing pregnancy rate beyond 20 weeks (18.4\%) however, it did not differ from those in Group 2. There was only one miscarriage in group 2.

\section{Discussion}

These data show that in women with extremely low AMH levels, clinical pregnancy rates of $15.9 \%$ and ongoing pregnancy rates beyond 20 weeks of $14.3 \%$ can be achieved. Although higher clinical pregnancy rate (18.4\%), and ongoing pregnancy rate $(18.4 \%)$ in women of $\leq 38$ years than women of $>38$ years of age (12 and $8 \%$ respectively) was noted, there was no significant difference which may be due to size of the sample.

Clinical pregnancy and ongoing pregnancy rates were lower in our cohort as compared to women with normal

Table 1. Demographics and hormone levels.

\begin{tabular}{|c|c|c|c|c|}
\hline & Total $(n=63)$ & Age $\leq 38$ years $(n=38)$ & Age $>38$ years $(n=25)$ & $\boldsymbol{P}$ \\
\hline BMI & $24(22-28)$ & $25(22-28)$ & $24(23-28)$ & 0.969 \\
\hline $\mathrm{AMH}(\mathrm{pmol} / \mathrm{L})$ & $2.1(0.6-3.7)$ & $2.5(0.7-3.7)$ & $1.5(0.6-2.9)$ & 0.2188 \\
\hline $\mathrm{FSH}(\mathrm{mIU} / \mathrm{ml})$ & $9.3(7-12)$ & $9.3(7.7-11.5)$ & $9.3(7-12)$ & 0.7455 \\
\hline
\end{tabular}

Median (interquartile range) Kruskal-Wallis test.

Table 2. Cycle outcomes in women with low AMH levels.

\begin{tabular}{|c|c|c|c|c|}
\hline & $\begin{array}{c}\text { Total } \\
(n=63)\end{array}$ & $\begin{array}{c}\text { Age } \leq 38 \text { years } \\
(n=38)\end{array}$ & $\begin{array}{c}\text { Age }>38 \text { years } \\
(n=25)\end{array}$ & $\boldsymbol{P}$ \\
\hline Gonadotrophin dose (IU) ${ }^{*}$ & $\begin{array}{c}4200 \\
(3900-4500)\end{array}$ & $\begin{array}{c}4200 \\
(3000-4500)\end{array}$ & $\begin{array}{c}4200 \\
(3900-4800)\end{array}$ & 0.466 \\
\hline Oocytes retrieved ${ }^{*}$ & $4(3-6)$ & $5(4-7)$ & $4(3-5)$ & 0.048 \\
\hline Cycle cancellation $^{* *}$ & $3(4.8)$ & $1(2.6)$ & $2(8)$ & 0.557 \\
\hline Clinical pregnancy $^{* *}$ & $10(15.9)$ & $7(18.4)$ & $3(12)$ & 0.726 \\
\hline Ongoing pregnancy rate beyond 20 weeks ${ }^{* *}$ & $9(14.3)$ & $7(18.4)$ & $2(8)$ & 0.297 \\
\hline
\end{tabular}

*Median (interquartile range) Kruskal-Wallis test. ${ }^{* *}$ No (\%). Fisher’s exact test. 
ovarian reserve (OR), however, these data show that even very low AMH levels do not rule out successful ART outcome. A relatively low cycle cancellation rate $(4.8 \%)$ is probably due to patient's wishes to go ahead with oocyte retrieval even with poor ovarian response to gonadotrophin stimulation.

The clinical pregnancy (15.9\%) and ongoing pregnancy rate (14.3\%) we report are comparable with other studies. Gleicher et al. [15] showed that women with extremely low AMH have relatively low (9.4\%) but reasonable chances of live birth after ART. Nelson et al. [6] have shown that women with $<5 \mathrm{pmol} / \mathrm{L}$ AMH can have $15 \%$ chances of live birth. Barade et al. [16] have shown that although the chances of pregnancy are low at AMH levels of less than $0.4 \mathrm{ng} / \mathrm{ml}$, pregnancies do happen even at undetectable levels of AMH because AMH loses predictive value for pregnancy at low levels. However, the results of the above mentioned studies needs careful interpretation because different AMH assay (Generation 1 DSL method) was used which has been shown to give less AMH values than Gen-2 AMH assay used in this study. Moreover, Weghofer et al. and Gleicher et al. supplemented their patients with DHEA which has been shown to improve pregnancy outcome in women with poor ovarian reserve [13] [15]. Two more recent studies by Kedem et al. [17] (20\% cumulative pregnancy rate after 5 cycles) and Lukaszuk et al. [18] (14\% clinical pregnancy and live birth rate respectively) have shown that women with extremely low AMH have reasonable chances of successful ART outcome.

Diminished ovarian reserve is a common cause of infertility in women seeking ART [19] and management of such women is challenging for fertility specialists [20]. Although women with diminished ovarian reserve have lower chances of pregnancy and live birth, younger women do better than older women [21]. Although low levels of AMH define diminished ovarian reserve with significantly low chances of pregnancy and live birth, it does not warrant withholding of treatment because even women with very low or undetectable AMH levels can still have reasonable chances of live birth [15]. Although AMH is highly correlated with ovarian response and the number of oocytes retrieved, it has limited value to predict pregnancy outcome [12] [22]. An alternative explanation of clinical pregnancies and ongoing pregnancy beyond 20 weeks in women with extremely low AMH levels can be due to significant intra-cycle variation in AMH levels [23] [24]. Moreover, AMH can have false negative values in $10 \%-15 \%$ cases [4]. Among our cohort of women with extremely low AMH levels, there is a possibility that a subset of women had false negative AMH values due to cyclical variation and as a result had better ART outcome as compared to the women who had truly reduced ovarian reserve. It is very difficult to identify women with false negative AMH value and it has been suggested testing both AMH and FSH simultaneously and if both of them are in abnormal range, those patients will have truly reduced ovarian reserve [25]. In the current economic constraints, funding agencies are limiting fertility treatment to women on the basis of age and ovarian reserve shown by different tests including AMH. Although the chances of live birth are reduced, it will be ethically difficult to withhold treatment just on the basis of low AMH levels when its performance to predict live birth is limited [12] [26].

We recognize that the small sample size and retrospective nature limit this study. A larger controlled study may confirm our data including whether the decreasing trend of clinical pregnancy and ongoing pregnancy rate in women with $\mathrm{AMH}$ of $<5 \mathrm{pmol} / \mathrm{L}$ with increasing age is real (group-2). However, the available literature on ART outcome in women with extremely low AMH levels is small and our findings add to that.

\section{Conclusion}

Women with extremely low-serum AMH levels can still have clinical pregnancy and ongoing pregnancy beyond 20 weeks after ART although the chances are much lower than women with normal ovarian reserve. They should be aware of the high risk of poor ovarian response and cycle cancellation.

\section{Acknowledgements}

We are grateful to Dr Ephia Yasmin for her useful suggestions to prepare this manuscript.

\section{Conflict of Interests}

None of the authors have any conflict of interest.

\section{References}

[1] Faddy, M.J., Gosden, R.G., Gougeon, A., Richardson, S.J. and Nelson, J.F. (1992) Accelerated Disappearance of Ovarian Follicles in Mid-Life: Implications for Forecasting Menopause. Human Reproduction, 7, 1342-1346. 
[2] Cahill, D.J., Prosser, C.J., Wardle, P.G., Ford, W.C.L. and Hull, M.G.R. (1994) Relative Influence of Serum Follicle Stimulating Hormone, Age, and Other Factors on Ovarian Response to Gonadotrophin Stimulation. BJOG: An International Journal of Obstetrics \& Gynaecology, 101, 999-1002.

[3] Hull, M.G.R., Fleming, C.F., Hughes, A.O. and McDermott, A. (1996) The Age-Related Decline in Female Fecundity: A Quantitative Controlled Study of Implanting Capacity and Survival of Individual Embryos after in Vitro Fertilization. Fertility and Sterility, 65, 783-790.

[4] La Marca, A., Sighinolfi, G., Radi, D., Argento, C., Baraldi, E., Artenisio, A.C., Stabile, G. and Volpe, A. (2010) AntiMüllerian Hormone (AMH) as a Predictive Marker in Assisted Reproductive Technology (ART). Human Reproduction Update, 16, 113-130. http://dx.doi.org/10.1093/humupd/dmp036

[5] Anderson, R.A., Nelson, S.M. and Wallace, W.H.B. (2012) Measuring Anti-Müllerian Hormone for the Assessment of Ovarian Reserve: When and for Whom Is It Indicated? Maturitas, 71, 28-33. http://dx.doi.org/10.1016/j.maturitas.2011.11.008

[6] Nelson, S.M., Yates, R.W. and Fleming, R. (2007) Serum Anti-Müllerian Hormone and FSH: Prediction of Live Birth and Extremes of Response in Stimulated Cycles-Implications for Individualization of Therapy. Human Reproduction, 22, 2414-2421. http://dx.doi.org/10.1093/humrep/dem204

[7] Nelson, S.M., Yates, R.W., Lyall, H., Jamieson, M., Traynor, I., Gaudoin, M., Mitchell, P., Ambrose, P. and Fleming, R. (2009) Anti-Müllerian Hormone-Based Approach to Controlled Ovarian Stimulation for Assisted Conception. Human Reproduction, 24, 867-875. http://dx.doi.org/10.1093/humrep/den480

[8] Nardo, L.G., Fleming, R., Howles, C.M., Bosch, E., Hamamah, S., Ubaldi, F.M., Hugues, J.N., Balen, A.H. and Nelson, S.M. (2011) Conventional Ovarian Stimulation No Longer Exists: Welcome to the Age of Individualized Ovarian Stimulation. Reproductive BioMedicine Online, 23, 141-148. http://dx.doi.org/10.1016/j.rbmo.2011.05.008

[9] Yates, A.P., Rustamov, O., Roberts, S.A., Lim, H.Y., Pimberton, P.W., Smith, A. and Nardo, L.G. (2011) Anti-Mullerian Hormone-Tailored Stimulation Protocols Improve Outcomes Whilst Reducing Adverse Effects and Costs of IVF. Human Reproduction, 26, 2353-2362. http://dx.doi.org/10.1093/humrep/der182

[10] Steiner, A.Z., Herring, A.H., Kenser, J.S., et al. (2011) Antimullerian Hormone as Predictor of Natural Fecundability in Women Aged 30-42 Years. Obstetrics \& Gynecology, 117, 798-804. http://dx.doi.org/10.1097/AOG.0b013e3182116bc8

[11] Broekmans, F.J., Kwee, J., Hendriks, D.J., Mol, B.W. and Lambalk, C.B. (2006) A Systematic Review of Tests Predicting Ovarian Reserve and IVF Outcome. Human Reproduction Update, 12, 685-718. http://dx.doi.org/10.1093/humupd/dml034

[12] Bhide, P., Gudi, A., Shah, A., Timms, P., Grayson, K. and Homburg, R. (2013) Anti-Müllerian Hormone as a Predictor of Pregnancy Following IVF. Reproductive BioMedicine Online, 26, 247-252. http://dx.doi.org/10.1016/j.rbmo.2012.11.018

[13] Weghofer, A., Dietrich, W., Barad, D.H. and Gleicher, N. (2011) Live Birth Chances in Women with Extremely Low Serum Anti-Mullerian Hormones Levels. Human Reproduction, 26, 1905-1909. http://dx.doi.org/10.1093/humrep/der134

[14] Kailasam, C., Hunt, L., Ryder, I., Bhakri, I. and Gordon, U.D. (2008) Safety and Effectiveness of Diclofenac Sodium in Assisted Reproduction Treatment: A Randomized Prospective Double-Blind Study. Reproductive BioMedicine Online, 16, 724- 729. http://dx.doi.org/10.1016/S1472-6483(10)60488-9

[15] Gleicher, N., Weghofer, A. and Barad, D.H. (2010) Antimullerian Hormone (AMH) Defines Independent of Age, Low versus Good Live Birth Chances in Women with Severely Diminished Ovarian Reserve. Fertility and Sterility, 94, 2824-2827. http://dx.doi.org/10.1016/j.fertnstert.2010.04.067

[16] Barad, D.H., Weghofer, A. and Gleicher, N. (2009) How Predictive of Basic Pregnancy Potential Are Extremely Low Levels of Anti-Mullerian Hormone (AMH). Fertility and Sterility, 92, 178-179.

[17] Kedem, A., Haas, J., Geva, L.L., Yerushalmi, G., Gilboa, Y., Kanety, H., Hanochi, M., Maman, E. and Hourvitz, A. (2013) Ongoing Pregnancy Rates in Women with Low and Extremely Low AMH Levels. A Multivariate Analysis of 769 Cycles. PLoS ONE, 8, e81629. http://dx.doi.org/10.1371/journal.pone.0081629

[18] Lukaszuk, K., Kunicki, M., Liss, J., Bednarowska, A. and Jakiel, G. (2014) Probability of Live Birth in Women with Extremely Low Anti-Müllerian Hormone Concentrations. Reproductive BioMedicine Online, 28, 64-69. http://dx.doi.org/10.1016/j.rbmo.2013.09.017

[19] Society for Assisted Reproductive Technology. IVF Success Rates, National Data Summary. http://www.sart.org/fram/detail.aspx?id=3893

[20] Coccia, M.E. and Rizzello, F. (2008) Ovarian Reserve. Annals of New York Academy of Sciences, 1127, 27-30. http://dx.doi.org/10.1196/annals.1434.011

[21] Check, J.R., Nazari, P., Check, M.L., Choe, J.K. and Liss, J.R. (2002) Prognosis Following in Vitro Fertilization- 
Embryo Transfer (IVF-ET) in Patients with Elevated Day 2 or 3 Serum Follicle Stimulating Hormone (FSH) Is Better in Younger vs Older Patients. Clinical Experimental Obstetrics Gynecology, 29, 42-44.

[22] Smeenk, J.M., Sweep, F.C., Zielhuis, G.A., et al. (2007) Antimullerian Hormone Predicts Ovarian Responsiveness, but Not Embryo Quality or Pregnancy, after in Vitro Fertilization or Intracytoplasmic Sperm Injection. Fertility and Sterility, 87, 223-226. http://dx.doi.org/10.1016/j.fertnstert.2006.06.019

[23] Overbeek, A., Broekmans, F.J., Hehenkamp, W.J., Wijdeveld, M.E., van Disseldorp, J., van Dulmen-den, B.E. and Lambalk, C.B. (2012) Intra-Cycle Fluctuations of Anti-Müllerian Hormone in Normal Women with a Regular Cycle: A Reanalysis. Reproductive BioMedicine Online, 24, 664-669. http://dx.doi.org/10.1016/j.rbmo.2012.02.023

[24] Wunder, D.M., Bersinger, N.A., Yared, M., Kretschmer, R. and Birkhäuser, M.H. (2008) Statistically Significant Changes of Antimullerian Hormone and Inhibin Levels during the Physiologic Menstrual Cycle in Reproductive Age Women. Fertility and Sterility, 89, 927-933. http://dx.doi.org/10.1016/j.fertnstert.2007.04.054

[25] Buyuk, E., Seifer, D.B., Younger, J., Grazi, R.V. and Lieman, H. (2011) Random Anti-Müllerian Hormone (AMH) Is a Predictor of Ovarian Response in Women with Elevated Baseline Early Follicle-Stimulating Hormone Levels. Fertility and Sterility, 95, 2369-2372. http://dx.doi.org/10.1016/j.fertnstert.2011.03.071

[26] Nelson, S.M. (2012) Chapter 25: The Patient with Poor Ovarian Reserve. In: Sharif, K. and Coomarasamy, A., Eds., Assisted Reproduction Techniques: Challenges and Management Options, Wiley-Blackwell, Oxford, 99-104. 
Scientific Research Publishing (SCIRP) is one of the largest Open Access journal publishers. It is currently publishing more than 200 open access, online, peer-reviewed journals covering a wide range of academic disciplines. SCIRP serves the worldwide academic communities and contributes to the progress and application of science with its publication.

Other selected journals from SCIRP are listed as below. Submit your manuscript to us via either submit@scirp.org or Online Submission Portal.
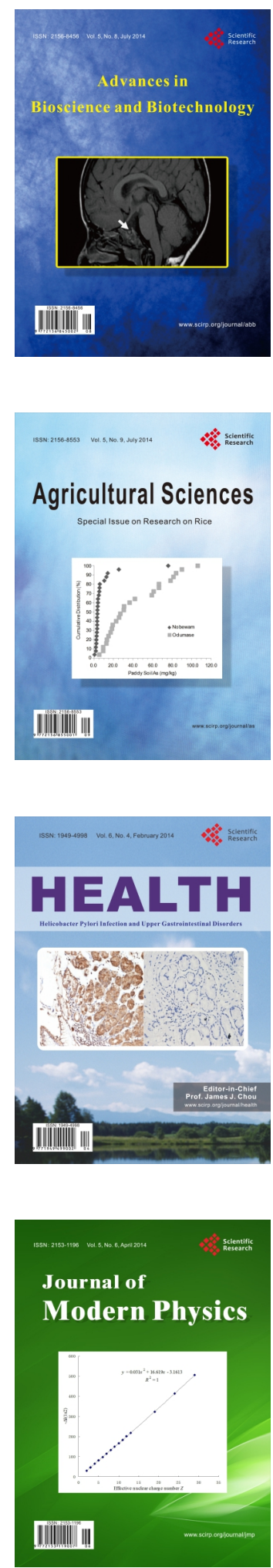
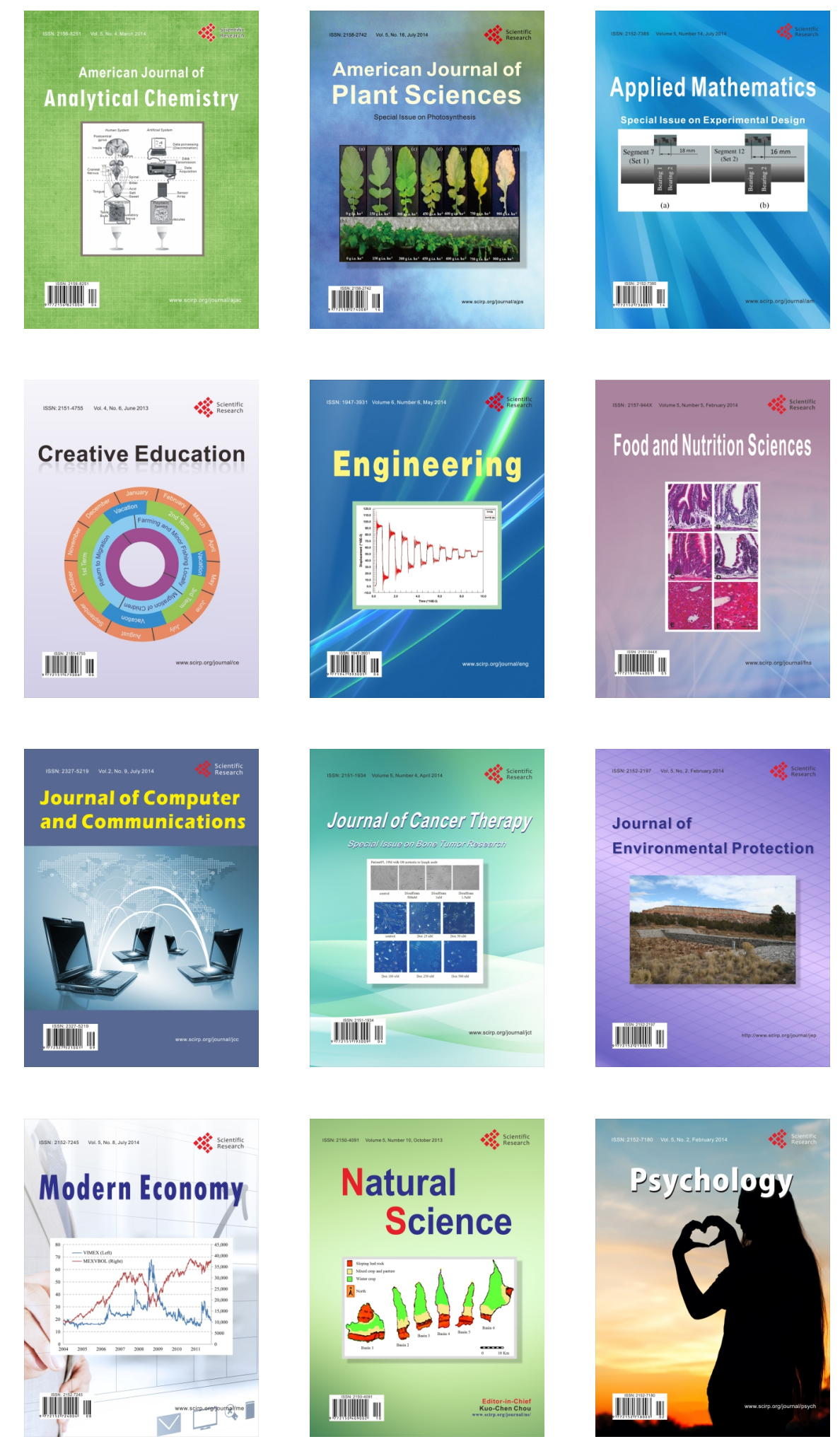